\title{
La amenaza cuna: política de indios del gobernador Andrés Ariza en el Darién durante su primera década de gobierno en el siglo XVIII*
}

\section{Nelson Eduardo Rodríguez Hernández}

\begin{abstract}
Afiliado institucionalmente a la Universidad de Manchester (Inglaterra). Correo electrónico: xnelsonrodriguezx@yahoo.com. El autor es Antropólogo e Historiador de la Universidad de los Andes (Colombia) y Candidato a magíster en Geografía de la Universidad de Manchester (Inglaterra). Entre sus publicaciones recientes tenemos: "El Imperio Contraataca: Las Expediciones Militares de Antonio Caballero y Góngora al Darién (1784-1790)", en Historia Crítica No. 53 (2014) y "Cartografía de la frontera "bárbara": las representaciones del Darién a propósito del conflicto entre el Virreinato de Nueva Granada y los Cuna", en Anuario de Historia Regional y de las Fronteras Vol. 19 No. 1 (2014). Entre sus temas de interés están etnohistoria atlántica, ecología política urbana y gobernabilidad ambiental.
\end{abstract}

Recibido: 7 de abril de 2014

Aprobado: 15 de octubre de 2015

Modificado: 2 de noviembre de 2015

Artículo de investigación científica

DOI: http://dx.doi.org/10.15648/hc.28.2016.8

* $\quad$ Este artículo forma parte del proyecto: "Bárbaros en el Corazón del imperio: interacción y disputa entre cunas y europeos en el Darién durante 1774-1792", realizado para la elaboración de la tesis de pregrado para obtener el título de historiador en la Universidad de los Andes (Colombia). Financiación solidaria.

- Agradezco a Carl Langebaek y al grupo de Historia Colonial de la Universidad de los Andes por los comentarios y sugerencias.

Esta publicación está bajo una licencia Creative Commons Reconocimiento-NoComercial 4.0. 


\title{
La amenaza cuna: política de indios del gobernador Andrés Ariza en el Darién durante su primera década de gobierno en el siglo XVIII
}

\section{Resumen}

Este artículo estudia la primera década del gobierno de Andrés Ariza en el Darién (1774-1784) y la respuesta de los grupos autónomos a sus iniciativas. El objetivo es presentar los dos ejes estratégicos para la reducción de los indígenas, analizando sus alcances y el impacto social en los pueblos cunas. Aborda un problema poco explorado por la historiografía colonial de la región y aporta elementos de análisis para el estudio de las fronteras hispano-indígenas de la América española, desde las particularidades del proceso de reducción y resistencia en el Darién.

Palabras clave: Darién, mundo Atlántico, cunas, reformas militares.

\section{The threat Cuna: Indian policy Governor Andres Ariza in Darien during its first decade of government in the eighteenth century}

\begin{abstract}
This article examines the first decade of Andres Ariza's government in Darien (17741784) and the autonomous groups' response to his initiatives. The aim is to present the two strategies in order to reduce indigenous people, analyzing their scope and social impact on Cuna peoples. Addresses a little explored issue by the colonial historiography of the region, and provides elements of analysis for the study of Spanish-Indian borders of the Spanish America, from the particularities of the reduction process and resistance in Darien.
\end{abstract}

Key words: Darien, Atlantic world, cunas, military reforms.

\section{A ameaça cuna: Política dos índios do governador Andrés Ariza no Darién durante a primeira década de governo no século XVIII}

\section{Resumo}

Este artigo estuda a primeira década do governo de Andrés Ariza no Darién (17741784) e a resposta dos grupos autônomos as suas iniciativas. O objetivo é apresentar os dois eixos estratégicos ao reduto indígena, analisando os seu alcance e impacto social nos povos cuna. Aborda um problema pouco explorado pela historiografia colonial da 
região e contribui elementos de analises para o estudo das fronteiras hispânico-indígenas da América espanhola, desde as particularidades do processo de redução e resistência no Darién.

Palavras chave: Darién, mundo atlântico, cunas, reformas militares.

\section{La menace originale: politique des indigènes du gouverneur Andrés Ariza dans le Darién pendant le premier décennie du gouvernement dans le XVIII siècle.}

\section{Résumé}

Cet article étudie la première décennie du gouvernement d'Andrés Ariza dans le Darién (1774-1784) et la réponse des groupes autonomes à ses initiatives. L'objectif est celui de présenter les deux axes stratégiques pour la réduction des indigènes, en faisant l'analyse de ses atteintes et de l'impact social dans les villages berceaux. Il aborde aussi un problème peu exploré par l'historiographie coloniale de la région et apporte des éléments d'analyse pour l'étude des frontières hispano indigènes de l'Amérique Espagnole, à partir des particularités du processus de réduction et résistance dans le Darién.

Mots clés: Darién, monde Atlantique, berceaux, réformes militaires.

\section{INTRODUCCIÓN}

Este artículo estudia la primera década de gobierno de Andrés Ariza en el Darién (1774-1784) y la respuesta de los grupos autónomos a sus iniciativas. El objetivo es presentar los dos ejes estratégicos para la disminución de los indígenas, ofreciendo información detallada del proceso de reducción y resistencia. El primer eje consistió en fortalecer los vínculos entre el virreinato y los líderes tribales. El segundo fue la implantación de guarniciones militares dispersas en la zona y la profesionalización de los efectivos militares. El argumento principal es que la política de poblamiento del gobernador Ariza impuso un sistema de ordenamiento territorial de pueblos en el Darién que fortaleció la burocracia indígena, pero que propició el saboteo al interior de las congregaciones indígenas y la militarización de los cunas no reducidos, facilitando la adapatación de los pueblos cunas a la ofensiva militar de la zona. Este aspecto es fundamental para entender 
los procesos de colonización y militarización fallidos en la región durante la segunda mitad del siglo XVIII.

\section{REFORMAS EN ÉPOCA DE INDÍGENAS BÁRBAROS}

Andrés Ariza hizo parte de los funcionarios que llegaron a América para mediar con los problemas estructurales de la administración colonial, en el marco de implementación de las Reformas Borbónicas ${ }^{1}$. Estas apuntaban, en el ámbito militar, a mediar con las tensiones inter-imperiales, la defensa de España y la respuesta frente a los indígenas no reducidos al orden colonial ${ }^{2}$. Los enfrentamientos con Inglaterra en ultramar alertaron a la Corona española de la necesidad de mejorar su sistema defensivo en América. En el virreinato de la Nueva Granada, los virreyes De la Cerda y Guiror resaltaban la importancia de traer soldados profesionales para reforzar la seguridad en las plazas marítimas. Inglaterra era una amenaza latente después de la toma de Cartagena (1741) y ellos advertían sobre la importancia estratégica de sus costas en el circuito territorial español. Esta preocupación se acentuaba por la existencia de grupos de indígenas que mantenían relaciones con los enemigos de la Corona ${ }^{3}$. En ese momento, los mosquitos de Nicaragua daban licencia a los ingleses provenientes de Jamaica para que se asentaran en sus costas ${ }^{4}$. Las alianzas entre bárbaros

1 Para conocer el contexto general de las campañas de frontera indígena en la América española en el marco de las Reformas Borbónicas véase David J. Weber, Spanish Bourbons and Wild Indians (Charles Edmondson Historical Lectures). (Waco, TX: Baylor University Press, 2004).

2 En el texto se utiliza el término Reforma, para hacer relación a la implementación de la política de indios desplegada por Andrés Ariza, en el marco de las Reformas Borbónicas y la confrontación de España contra los indígenas no sujetos a la administración colonial. Véase. Allan Kuethe, "Carlos III: absolutismo ilustrado e imperio americano", en Soldados del Rey: El ejército borbónico en América colonial en vísperas de la independencia. Ed: Allam Kuethe y Juan Marchena, Barcelona: Universidad Jaume I, 2005, 17-30. Para conocer el contexto de rivalidad inter-imperial que sustentaron a Reformas, véase. John Fisher, 'Imperial reforms and rivalries", en: Thomas H. Holloway, ed. A companion to Latin American history (John Wiley \& Sons, 2011).

3 Pedro Messia De la Zerda, "Relación del estado del virreinato de Santa Fe", (1772), en: Relaciones e informes de los gobernantes de la Nueva Granada. ed: Germán Colmenares (Bogotá: Banco Popular, 1989), Vol. 1. 144-150; Manuel Guiror, "Instrucción que deja a su sucesor en el mando" en: Relaciones e informes de los gobernantes de la Nueva Granada. ed: Germán Colmenares (Bogotá: Banco Popular. 1989). Vol. 1, 334-354.

4 Manuel Guiror, "Instrucción que deja a su sucesor en el mando".... 362. Para conocer sobre este proceso de integración en otros contextos, véase: Claudia García, Etnogénesis, hibridación y consolidación de la identidad del pueblo Miskitu, (Madrid: Consejo Superior de Investigaciones Científicas, 2007); Nicholas Rogers, "Caribbean Borderland. Empire, Ethnicity, and the Exotic on the Mosquito Coast”, en Eighteenth-Century Life, Vol. 26, No. 3. 
e ingleses era una de las razones para emplear mejoras en la tropa y sus actividades.

Pero los mosquitos no eran los únicos que, con complicidad de extranjeros, hostilizaban los poblados españoles en el Virreinato de la Nueva Granada. En Veraguas los guamiles, ubicados al sur de la intendencia de Nicaragua, se convirtieron en una amenaza permanente para las inmediaciones de la provincia, debido al apoyo de algunos extranjeros ${ }^{5}$. No solo los ingleses mantuvieron relaciones con grupos indígenas al margen del poder español. En el sur del virreinato, en límites con Brasil, los indígenas establecieron relaciones de intercambio con colonos portugueses, que preocupaban a los virreyes. No obstante, estos lugares eran aún más remotos para el control español que las fronteras indígenas de la costa Atlántica, por lo que desconocían la situación y los alcances de dichas relaciones. La existencia de grupos indígenas autónomos, como los que se mencionaron, era preponderante en el continente y el problema que estos representaban para afianzar el control territorial y la expansión de las áreas productivas, por ejemplo en la intendencia de Chile y el virreinato de La Plata, condujo a un reordenamiento de las estrategias militares y de evangelización en el continente ${ }^{6}$.

La evangelización era efectiva con algunos indígenas ubicados en el Virreinato de la Nueva Granada. Por ejemplo, las labores de cristianización adelantadas entre los grupos motilones, de la Serranía del Perijá y la Bahía de Maracaibo, según los informes de la época, consiguieron, por momentos, mediar con sus hostilidades ${ }^{7}$. En efecto, esta empresa tenía mejores réditos que la capuchina de La Guajira, donde fueron enviados religiosos después de la toma indígena de Rio Hacha en 1769. La particularidad del Darién, en ese conjunto de iniciativas de reducción militar y religiosa, era la poca eficacia entre los cunas. Por el contrario, durante los años de evangelización en otros territorios del virreinato, los grupos autónomos darienitas

5 Francisco Antonio Moreno y Escandón, "Estado del virreinato de Santafe", 170.

6 David Weber, Barbaros: los españoles y sus salvajes en la era de la Ilustración (Madrid: Crítica, 2005), 207-266.

7 Pedro Messia De la Zerda, "Relación del estado del virreinato de Santa Fe", 125-128. 
afianzaron el control territorial en los vacíos de administración colonial, como se mostrará para el caso del gobernador Andrés Ariza ${ }^{8}$.

En esa coyuntura surgieron instructivos para la pacificación, erigidos desde los virreyes, que consistían en atraer a los indígenas con regalos, en especial utensilios productivos. Estos eran dirigidos a los grupos que habitaban las fronteras españolas. Los religiosos se adentraban a los bosques ofreciendo herramientas, las cuales eran intercambiadas, en su óptica, por la reducción a la vida cristiana. El virrey Guiror consideraba que estos métodos eran provechosos, pero era consciente que algunos religiosos se sobrepasaban en el trato con los indígenas, lo que desencadenó levantamientos al interior de los pueblos, como en Quito?.

Las tensiones entre españoles e indígenas, a consecuencia de la avanzada religiosa y militar, llevó a que las autoridades identificaran dos tipos de indígenas contrarios al orden. Por un lado se encontraban los indígenas "bárbaros", de los que hacían parte los cunas, mosquitos y guajiros ${ }^{10}$. Y por otro, indios gentiles que habitaban en los pueblos. De manera que la restructuración de la política indígena tuvo dos vertientes, una fueron las transformaciones en el funcionamiento y organización de las milicias de la Corona y, otra, una vigilancia al trato de los religiosos hacia los indígenas. En el caso del Darién, ambas iniciativas se desarrollaron de manera paralela, debido a la existencia de indígenas reducidos (que los españoles creían como tales) y de grupos autónomos.

Mientras los motilones, guajiros y mosquitos hostilizaban los pueblos españoles ubicados en sus territorios, los cunas expandían su radio de presencia a través del saboteo militar. Las plazas marítimas del virreinato, ante

8 Sobre los proyectos de evangelización de la década del cuarenta: Ignacio Gallup Diaz, "The Spanish Attempt to Tribalize the Darién, 1735-50", Ethnohistory 49: 2 (2002): 281-317; Carl Langebaek, El diablo vestido de negro y los cunas del Darién en el siglo XviII (Bogotá: Uniandes, 2006).

2169 Francisco Antonio Escandón y Moreno, "Estado del virreinato de Santafe"... 190.

10 Bárbaros hace referencia a la categoría colonial para denominar a los indígenas autónomos no reducidos que se mantuvieron en confrontación permanente con los imperios del Atlántico. Véase: David Weber, Bárbaros: los españoles y sus salvajes... 
este panorama, eran archipiélagos contenidos por la avanzada de grupos autónomos, donde no existía una articulación logística efectiva de las gobernaciones ${ }^{11}$. Las hostilidades y su respuesta, como consecuencia, obligaron a destinar recursos que las dependencias respectivas solicitaban a España. En la mayoría de los casos los funcionarios no recibían el presupuesto que solicitaban y veían con impotencia la expansión territorial de los cunas.

\section{Autodefensa vecinal, tensiones en la frontera Cartage- NA-PANAMÁ}

En el Darién, desde finales de los 60 y hasta la llegada de Ariza, no se desarrollaron campañas militares amplias, a diferencia de La Guajira y Maracaibo, sino expediciones esporádicas dirigidas por funcionarios de la zona. No obstante, la situación conflictiva obligó a la respuesta de los vecinos que habitaban las fronteras de Panamá y Cartagena, donde los "bárbaros" cometían asesinatos, raptaban indígenas conversos e incendiaban los pueblos de Lorica ${ }^{12}$. La Gobernación de Cartagena, en ese caso, sirvió de apoyo logístico para que los vecinos se armaran. Las primeras respuestas consistieron, por lo tanto, en fomentar acciones de autodefensa, acompañadas de pocos efectivos miliares de la plaza de Cartagena ${ }^{13}$.

Las primeras expediciones vecinales se dirigieron al río Sinú con el pro-

11 Agustín Crame organizó un plan para defender la plazas de Panamá y algunos flancos del istmo como Chagres y el Darién, consistía en articular la defensa de la costa, pero conservando la autonomía a algunas plazas para que puedan responder ante ataques imprevistos. Esto no se realizó. AGMM. Fondo de Ultramar. Rollo (GD.58.5-2-7-1). "Plan de defensa de la plaza e istmo de Panamá”. Agustín Crame. 1779.

12 También hubo algunas expediciones organizadas desde Portobelo dirigidas a las inmediaciones de Calidonia, que estuvieron conformadas por negros e indígenas dirigidos por militares del batallón fijo de Panamá, por ejemplo: Archivo General de la Nación. Sección Colonia. Fondo Historia Civil. Legajo 20. "1773-1777. Nicolás Quijano, de Panamá y su cooperación en la conquista de los indígenas del Darién y notas sobre el mismo asunto". 1773, f. 1-5.

13 Archivo General de la Nación (AGN), Sección Colonia. Fondo Historia Civil. Legajo 14. "Sobre protección de la navegación en el Sinú, contra hostilidades de los indígenas del Darién y medidas que se tomarán para combatirlos". 1768-1770, f. 923-1006. 
pósito de identificar los lugares donde habitaban los "bárbaros"14. Los vecinos de Tolú decidieron tripular la piragua que tenían a su disposición, pero pedían apoyo para adentrarse a la zona con embarcaciones enviadas desde Cartagena ${ }^{15}$. Manuel de la Torre, el alcalde de este pueblo, impulsó la incursión en el río. Para tal fin, el cabildo le solicitó que las balandras que arribaban al pueblo con víveres fueran utilizadas durante las incursiones. Las primeras capturas realizadas en las expediciones de piraguas del Sinú, al mando de Martín Vásquez, delegado de Cartagena, indicaban que los indígenas del río Bayano, en Panamá, hostilizaban en las inmediaciones de Lorica y Tolú. Ellos eran dirigidos por un tal "cacique" Bernabé ${ }^{16}$. Con el tiempo, las incursiones vecinales fueron reforzadas por algunos soldados de la guarnición fija cartagenera ${ }^{17}$. Estas expediciones por el Sinú fortalecieron las labores de guardacostas, con el propósito de contener no solo a los grupos autónomos sino a los extranjeros. No obstante, los viajes exponían a las personas que permanecían en las fundaciones, lo que permitió a los cunas incendiar los pueblos mencionados, además de asesinar a algunos de sus vecinos.

Ante la desprotección de los poblados, la Gobernación de Cartagena despachó 50 hombres armados, pero sin efecto, debido al cambio de estrategia de los grupos autónomos:

"En cuya inteligencia y en la de que los expresados indios, ya han variado de sistema, introduciéndose por su misma costa, para venir por tierra, y con toda seguridad a la del Sinú, premeditando también que el abandono de aquellos vecinos, es lo que ocasiona semejantes desgracias"

14 Esta zona tenía presencia mayoritariamente de grupos zinues, pero en los informes se hace explícito que los indígenas de las hostilidades eran cunas, ya que durante los interrogatorios a los cautivos confesaban habitar las costas de Calidonia.

15 AGN. Sección Colonia. Fondo Historia Civil. Legajo 14. "Las providencias contra los indios bárbaros del Darién". Pedro De la Cuesta. 1770, f. 918.

16 AGN. Sección Colonia. Fondo Historia Civil. Legajo 14. "Las providencias contra”, f. 946.

17 AGN. Sección Colonia. Fondo Historia Civil. Legajo 14. "Las providencias contra”, f. 953.

18 AGN. Sección Colonia. Fondo Historia Civil. Legajo 14. "Las providencias contra”, f. 954. 
Ante los ataques de los indígenas no reducidos, el virreinato ordenó al ingeniero militar Antonio de Arévalo la elaboración de unos planos, con el fin de examinar el lugar más oportuno para construir un fuerte que contuviese el comercio extranjero y que sirviera de aduana ${ }^{19}$. Su proyección se hizo en el río Caimán ${ }^{20}$. Este sería el primer fuerte de los que se intentaron construir en las inmediaciones del territorio cuna. El ingreso tendría dos frentes, el primero, desde Cartagena, cuyo centro de operaciones fue Tolú. El otro provenía desde Panamá, proyectado a contener los poblados del archipiélago de las Mulatas y los del interior del Darién.

La Gobernación de Panamá era responsable de la protección del Darién y Veraguas $^{21}$. Ambas provincias representaron gastos que esta dependencia no conseguía asumir. Los indígenas autónomos, tanto los que asediaban las inmediaciones de Veraguas por el norte de la gobernación, como los del sur en la región ístmica, impedían la expansión productiva y dificultaban la extracción de recursos aptos para su comercialización. Esta situación era reforzada por la presencia de contrabandistas en los puertos de Portobelo y Veraguas, quienes conseguían acceder a los productos interinos ${ }^{22}$. Se consolidó un circuito económico afuera del orden virreinal, por un lado, de contrabandistas locales, ingleses de Jamaica y holandeses de Curazao; por otro, de indígenas autónomos que intercambiaban sus productos por armas, ropas, y utensilios provenientes de estas islas. Ante este panorama, el virreinato necesitó disciplinar sus efectivos militares y reforzar la asistencia financiera de Panamá. Se aprobaron recursos provenientes del virreinato del Perú para adelantar expediciones que permitieran la protección de las costas. Para estas expediciones, las autoridades solicitaron

19 Francisco Moreno y Escandón, "Estado del virreinato de Santa Fe, Nuevo Reino de Granada"... 180.

20 El río Caimán, según las proyecciones de la época, era un afluente del Atrato cercano al río Turbo.

21 Manuel Guiror, "Instrucción que deja a su sucesor en el mando", 348.

22 El problema del contrabando hace parte de otro fenómeno distinto al del intercambio de bienes de lujo de indígenas autónomos; no obstante, la presencia de contrabandistas completaba el escenario donde los europeos no españoles afectaban, con su comercio, la seguridad de las costas y plazas marítimas. Véase, Juan Sebastián Gómez Gonzales, "Las tensiones de una frontera ístmica: alianzas, rebeliones y comercio ilícito en el Darién, siglo XVIII”. Historia y Sociedad No. 15 (2008): 143-163. 
recursos a La Habana para mejorar la navegación de los guardacostas que se desplazaban entre Cartagena y Panamá ${ }^{23}$.

Antes de la llegada de Ariza, el comandante del Darién era Manuel Sonria, quien mantenía unas decenas de vecinos armados en los cuatro poblados existentes (ver Cuadro 1). Allí habitaban personas desterradas de Cartagena y Panamá, además de algunos esclavos que fueron llevados a la zona para adelantar labores de extracción de oro. Los pueblos tenían un número reducido de vecinos, sin más de 80 hombres de guarnición. En esta situación se planteó el abandono del principal lugar productivo, el pueblo de Cana, porque era vulnerable a las incursiones de piratas e indígenas que saqueaban las cajas reales de la Provincia ${ }^{24}$. La inseguridad y precariedad de las construcciones, llevó a la Gobernación de Panamá a construir Yavisa, donde se erigió el primero de los fuertes militares en la zona y viviría el gobernador de momento. Este pueblo se convirtió en la capital de la provincia en 1770, aunque había sido fundado en el 60.

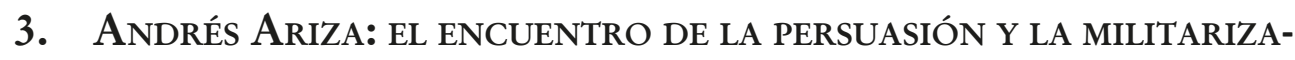 CIÓN}

La primera década de gobierno de Andrés Ariza, como ya se mencionó, ilustra la implementación de las reformas militares en la América española en el Darién. Los intentos por congregar a los indígenas en un sistema de pueblos se apoyó de dos estrategias, la primera, a través de medidas persuasivas como la entrega de presentes a los cunas y el fortalecimiento de cargos militares al interior de los indígenas reducidos. La segunda, a través de la militarización del Darién, con la creación de fuertes militares y el entrenamiento de efectivos locales para contener a los cunas. Los primeros años del gobierno de Ariza se presentarán en dos secciones. La primera,

23 Francisco Moreno y Escandón, "Estado del virreinato de Santa Fe, Nuevo Reino de Granada", 202. 24 AGMM. Fondo de Ultramar. Rollo (G.D. 57. 5-2-6-5) "Discurso sobre los reparos necesarios para la defensa del istmo de Panamá y advertencias criticas del estado de las milicias y plazas”. 1771 AGN. Sección Colonia. Fondo Milicias y Marina. Legajo 118. "Pueblo de Cana: provincia del Darién, su extinción.”1771, f. 30-31. 
la persuación a los líderes tribales, y la segunda, la construcción de fuertes militares. Estas dos estrategias eran parte de la historia de las relaciones de confrontación hispano-indígena en América en el marco de las Reformas Borbónicas.

El gobernador Andrés Ariza se posesionó ante pueblos desolados. Sus labores iniciales consistían en informar a los burócratas de Madrid sobre la situación del Darién, después buscar estrategias para conseguir recursos que permitieran aumentar el caudal de gastos militares en la defensa de las plazas marítimas. Sus indagaciones pretendieron conocer las circunstancias de la región, el modo de vivir de sus gentes, en especial "dar exactas noticias de sus circunstancias, especialmente de los indios, que prometo que habiendo ellos sido la causa de su desgracia contribuían ahora a hacerla feliz" ${ }^{25}$.

Los postulados de la gobernación de Ariza, como la apuesta por forjar alianzas con líderes tribales e impulsar el poblamiento del territorio, hicieron parte de las medidas propiciadas por pensadores reformistas que reflexionaron sobre el problema de los indios bárbaros en sus territorios ${ }^{26}$. Desde mediados del siglo XVIII algunos funcionarios de la Corona española consideraban que el comercio y los presentes a los indios traerían mejores réditos en su reducción y aliviarían la carga presupuestal del imperio. En el caso del Darién, Ariza intentó persuadir a los indígenas, reforzando cargos militares como el de cacique-capitán, quienes recibían presentes a cambio de velar por la disciplina al interior de la congregación en los congredos de indios. Los pueblos de la zona donde existían estas figuras quienes tenían a su cargo indígenas recién conversos, por lo tanto no tributarios, y vecinos españoles ${ }^{27}$, eran:

25 Andrés Ariza, “Comentarios de la rica y fertilísima provincia del Darién 1774”, en: La gobernación del Darién a finales del siglo XVIII, 38.

26 Manuel Lucena Giraldo sostiene que muchos estudios que analizan el papel de los funcionarios de esta época desconocen el contexto general de las discusiones reformistas. Véase: Manuel Lucena Giraldo, "Las nuevas poblaciones de Cartagena de Indias. 1774-1794". Revista de Indias, Vol. LIII, No. 199 (1999): 762-781.

27 Andrés Ariza, Detalle de la provincia del Darién (1774), en: La gobernación del Darién a finales del siglo XVIII, 31-77. 


\section{Cuadro 1.}

Pueblos que existían antes de la llegada de Ariza

\begin{tabular}{|c|c|c|c|c|c|c|}
\hline Pueblo & $\begin{array}{c}\text { N. de } \\
\text { vecinos }\end{array}$ & Estatus & $\begin{array}{c}\text { N. de hombres } \\
\text { en armas }\end{array}$ & Productos & Guarnición & Afluente \\
\hline Yavisa & 170 & $\begin{array}{l}\text { Pardos y } \\
\text { españoles }\end{array}$ & 59 & & Mampostería & Chucunaque \\
\hline $\begin{array}{c}\text { Real de } \\
\text { Santa María }\end{array}$ & 180 & $\begin{array}{l}\text { Pardos y } \\
\text { españoles }\end{array}$ & 26 & & $\begin{array}{c}\text { Palmas } \\
\text { y estacas }\end{array}$ & Pierre \\
\hline Cana & 26 & $\begin{array}{l}\text { Pardos, } \\
\text { españoles y } \\
\text { esclavos }\end{array}$ & 10 & Oro & $\begin{array}{c}\text { Palmas } \\
\text { y estacas }\end{array}$ & \\
\hline Chapigana & 5 & $\begin{array}{l}\text { Pardos y } \\
\text { españoles }\end{array}$ & 26 & & $\begin{array}{c}\text { Palmas } \\
\text { y estacas }\end{array}$ & Río Tuira \\
\hline Tichichi & 170 & Indios & $?$ & $\begin{array}{l}\text { Cacao, } \\
\text { maíz }\end{array}$ & - & \\
\hline Pinogana & 180 & Indios & $?$ & Cacao & - & \\
\hline Morineca & - & Indios & & & & \\
\hline Tucuty & & Pardos & & & & \\
\hline
\end{tabular}

Fuente: Elaborado por el autor con base en las descripciones del Gobernador Andrés Ariza

Los ingenieros militares se dirigieron a estos pueblos para conocer las costumbres cunas. Sus informaciones, más que ser observaciones de carácter etnológicos, son el reflejo de la perspectiva oficial sobre los indios reduci$\operatorname{dos}^{28}$. Las descripciones retratan la organización al interior de los pueblos porque tenían el interés de conocer sus jerarquías (Ver Imagen 1) ${ }^{29}$.

Sus primeras impresiones les permitieron identificar la relación entre leres, camotunos y uranaias. También estaban algunos caciques-capitanes,

28 Sobre la información etnológica cuna que contienen estos documentos, Jaime Peralta Aguádelo sostiene que "los documentos coloniales no solo son una fuente importante de conocimiento que permite realizar un acercamiento etnohistórico a los conocimientos y destrezas médicas de los cuna del pasado, sino que estos textos son un reflejo directo de la forma de pensar y de comportarse de las élites coloniales frente a la diferencia cultural que estaban hallando en esta sección del virreinato neogranadino". Véase: Jaime Peralta, "Los cuna y sus saberes médicos. La ciencia de los bárbaros bajo la mirada del mundo ilustrado", en: Historia Crítica No. 46 (2012): 44-65.

222 Andrés Ariza, "Noticia de algunos propietarios de los indios gentiles de la Provincia de Santa María la Antigua del Darién: Cual es el instituto de los principales magnates de sus pueblos: y el modo de proporcionar sus hostilidades contra los españoles". 1774, en: La gobernación del Darién a finales del siglo XVIII. 
quienes apoyaban la defensa de los poblados ante las hostilidades de indígenas autónomos. Este cargo se daba por línea de consanguinidad, pero la implantación del sistema de asentamientos virreinales llevó a que lo asumieran indígenas cercanos al vierrinato con perfil militar, "la burocracia indígena”. En estas descripciones, distinguían a los leres, a quienes los funcionarios no daban importancia social. Sin embargo, ellos propiciaron el rechazo y la desconfianza a los españoles, y posiblemente fueron los principales agentes de saboteo al interior de los pocos pueblos de indios en la región ${ }^{30}$. Esto fue confirmado desde la llegada en rigor de las fuerzas evangelizadoras $^{31}$.

\section{Imagen 1}

Mapa que representa el curso de los ríos que fertilizan el curso de la provincia de Santa María la Antigua del Darién ${ }^{32}$

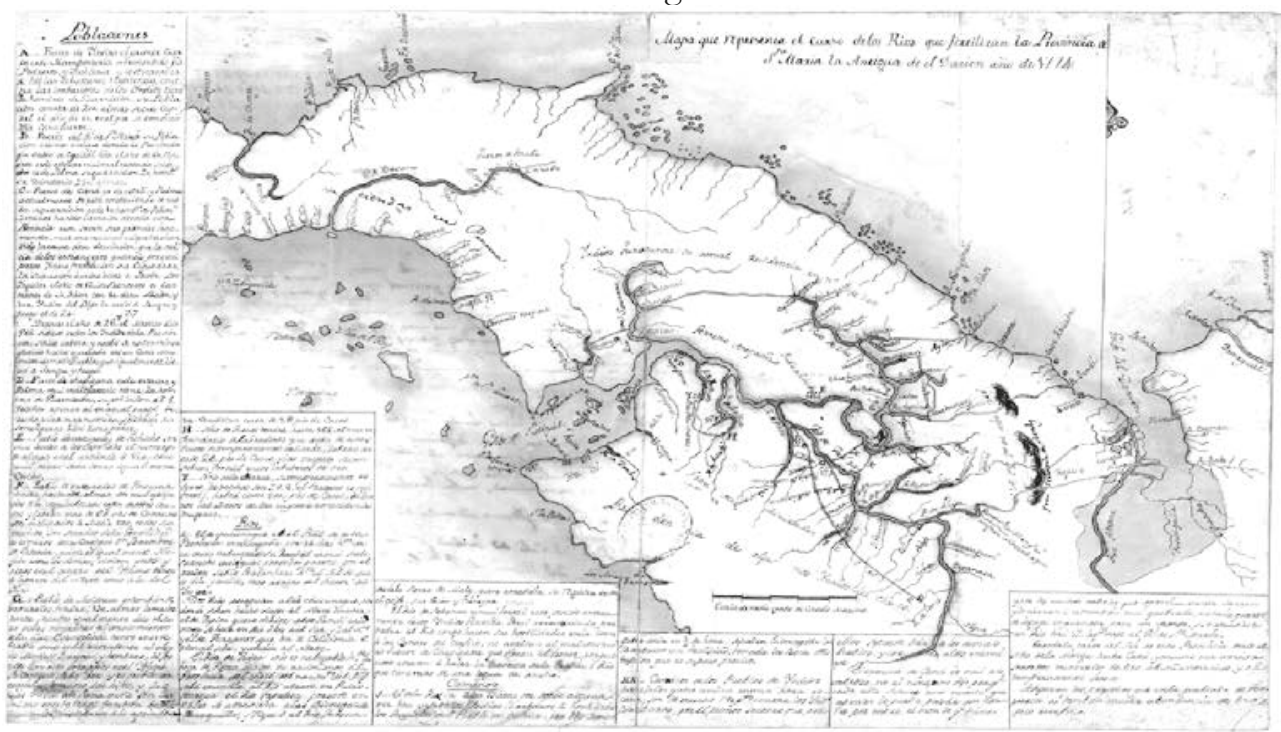

Fuente: Andrés Ariza. Archivo General Militar de Madrid, Cartoteca, 1774

Los funcionarios descartaron la relevancia social de los leres, pero les atri-

30 Antonio Arévalo, "Provincia del Darién...", 42-45.

31 Jacobo Walburguer, "Relación de la provincia del Darién" (1748), en: El diablo vestido de Negro, 91.

32 Además de ubicar el curso de los ríos, principalmente los que están en las inmediaciones de los asentamientos que controla el gobernador, Ariza describe la situación de cada uno de los poblados y pequeños fuertes de la provincia, presenta un censo del estado militar, ofrece datos históricos de las incursiones extranjeras y resalta los caminos que comunican los distintos poblados. 
buían poderes para la curación de enfermedades. Antonio de Arévalo se impresionó con sus habilidades para producir sonidos selváticos durante los rituales. Su poder rebozaba lo ritual y en algunos casos eran responsables de las expediciones contra los poblados españoles. Los camotunos eran quienes tocaban el camo (flauta) durante las ceremonias y bailes que denominaban “guayacán”. Este cuadro lo completaba el urania, encargado de impulsar el asesinato a españoles. Ellos se hallaban a las afueras de los poblados y su principal característica era el dominio de la noche ${ }^{33}$.

Los ingenieros militares también estuvieron en las salidas de cacería colectiva, en las cuales se desplazaron al monte con los indígenas. Los recorridos duraban 20 días, en la búsqueda de jabalíes, pajulies, monos negros e iguanas. Arévalo comenta que las salidas de caza se acompañan con chi$\mathrm{cha}^{34}$. Las herramientas que les ofrecían los españoles, como las hachas y las escopetas, eran utilizadas durante la caza, pero continuaban usando elementos propios como las flechas. Antonio de Arévalo, para sustentar sus relatos, decía "así lo experimenté en los viajes que hice con los parciales, quienes siguen con todo su método" 35 .

La información sobre los nativos recolectada en los primeros acercamientos a los pueblos reducidos, afianzó la idea en Ariza de reforzar la burocracia indígena del virreinato. Para ese momento, los pueblos de indios tenían una estructura administrativa que funcionaba de la siguiente manera:

"Para el Gobierno político que tienen entre sí estos tres pueblos (de indios), hay en cada uno un Cacique, que es el Jefe superior con 15 pesos de sueldo al mes, y de los indios de mayor distinción hay un Capitán, un Ayudante, un Teniente y un Alférez con patentes del Gobernador de Panamá, y aunque no tienen sueldo se presentan con mucha decencia y ostentación. Asociados de 
estos magnates el resto de los pueblos respectivos nombran cada año para las administraciones de justicia dos Alcaldes, que para su confirmación vienen á esta capital, y el Gobernador en señal de posesión, les entrega la vara, haciéndoles la correspondiente arenga. También nombran dos Alguaciles, con cuyas cabezas se mantienen los pueblos tan exactamente gobernados, que no tienen que envidiar á los más cultos"36.

Como ya se sugirió, Ariza centró sus esfuerzos en fortalecer las relaciones con los caciques-capitanes, a través de presentes útiles para la cacería y el pago por contener a los indígenas recién conversos en los pueblos. El principal funcionario nativo, durante este periodo, fue el cacique de Pinogana Bartolomé de Estrada. También un criollo de Cartagena que se desempeñó como intérprete, Juan Rafael Simancas, quien había sido capturado en su niñez por un pirata francés que transitaba las costas de Tolú. Ellos atraían indígenas a los pueblos existentes, a través de presentes, principalmente escopetas y machetes.

Bartolomé de Estrada, con el tiempo, se convirtió en comandante de las piraguas guardacostas del Darién. Sus diarios son testimonio de las expediciones contra los cunas autónomos. Las expediciones que comandaba salían de Lorica y Tolú con el objetivo de realizar reconocimientos en Calidonia. Estas afrontaron varios inconvenientes, ya que los trayectos eran largos y no contaban con suficientes provisiones. Además, las expediciones eran conformadas por pocos soldados de la guarnición de Cartagena, con escaso armamento para los vecinos de su tripulación. Pero el mayor inconveniente fue la inferioridad de sus escuadrones frente a los ataques de indígenas, quienes los hostilizaban en las inmediaciones de los ríos y las costas de Urabá. A pesar de no tener mayor efectividad en la reducción de las hostilidades a los poblados de Lorica y Tolú, Bartolomé García consiguió identificar los lugares donde indígenas e ingleses intercambiaban productos. Este cacique-capitán pretendía acceder a los poblados autónomos

36 Andrés Ariza, "Comentarios de la rica y fertilísima provincia del Darién...", 40. 
a través de presentes. Por eso sus escuadrones no solo eran compuestos por vecinos españoles, sino también participaron indígenas conversos que dialogaban cuando sus embarcaciones no eran atacadas. Sin embargo no se relacionó exitosamente con ninguno de los grupos autónomos.

En junio de 1774, durante su primera expedición, solo consiguió asesinar a un indígena que portaba una cabellera inglesa, una escopeta y pólvora holandesa ${ }^{37}$. Bartolomé Estrada pretendía capturar rebeldes que pudiera interrogar para conocer los movimientos de extranjeros enemigos. Esto lo consiguió tres años después; el capitán Estrada capturó a algunos indígenas que vivían en las inmediaciones de Calidonia. Su estrategia, para que tuviera réditos, fue negociar su libertad a cambio de información útil.

Los cuestionarios que implementó con los cautivos indagaban por el nombre, pueblo, empleo, "modo de pagar su vida” y demás concerniente al interior de los pueblos autónomos. El indígena más viejo del grupo capturado se llamaba "Chue-lere", de Ganor, quien respondió no tener ningún empleo y "que pasaba su vida haciendo rozas"38. Bartolomé García le preguntó por los poblados y su funcionamiento. Este respondió que él conocía el poblado y este no excedía las 20 casas, pero todos contaban con varias piraguas. Estas, a diferencia de las balandras del virreinato, no tenían cañoneros.

Lo que más le interesó a García fue que en estos poblados frecuentaban varios ingleses. Ellos intercambiaban armamento, el cual era guardado en las costas para hostilizar a las expediciones virreinales desde las márgenes de los ríos. Los ingleses permanecían algún tiempo con los indígenas, después volvían al mar y posteriormente llevaban embarcaciones llenas de frutos de la zona. Según Chue-lere, la mayoría de pueblos realizaban lo piraguas guardacostas del Darién, su diario sobre movimiento de naves". 1774, f. 119.

38 AGN. Sección Colonia. Fondo Milicias y Marina. Legajo 80. Bartolomé García "Piraguas del Darién: informe de sus actividades contra los indios de la región", f. 836-847. 
mismo. Así intercambiaban escopetas los indígenas y pedreros ${ }^{39}$. También le confirmó que varios de ellos eran aptos para utilizar las armas, como por ejemplo en Calidonia que "es el mayor de todos (los pueblos) y de mucha gente fuerte en ánimo y armas; y que allí abundan los ingleses" ${ }^{40}$. Bartolomé García cerró el interrogatorio preguntando sobre la relación que tenían los tres indígenas. Ellos manifestaron que uno era de Arquía y que vivía en Gandi debido a que se había casado con una de las hijas de Chue-lere; el otro era un niño, nieto del anciano. Esto puede ser indicio de relaciones exogámicas amplias entre los cunas, como estrategia para fortalecer redes intergrupales dispersas por los ríos del Darién ${ }^{41}$.

En estos años que se intensifica la presencia militar del virreinato, no solo se fortaleció la "burocracia indígena" a través de los capitanes, sino también la figura del capitán de los grupos autónomos. En otros documentos, a propósito de este tema, los funcionarios que realizaban expediciones argumentaban que el poder de estas figuras recaía en la coerción y el despotismo de quienes se afianzaban como líderes. Posiblemente, los capitanes de los grupos autónomos, sí existieron, hicieron presencia en la región para finales del siglo XVIII, producto de la militarización del Darién, ya que los análisis etnográficos no identifican líderes que ejercieran poder cohercitivo al interior de las comunidades ni tampoco hay personajes en los relatos míticos de características despótico-guerreras.

39 Pedrero: Boca de fuego antigua, especialmente destinada a disparar pelotas de piedra. Real Academia de la Lengua Española. Edición 1780.

40 AGN. Sección Colonia. Fondo Milicias y Marina. Legajo 80. Bartolomé García "Piraguas del Darién: informe de sus actividades contra los indios de la región”, 1777, f. 845.

41 El sistema de parentesco entre los cunas que habitan las islas de San Blas es bilineal, uxorilocal y de corte exogamico estricto, véase. James Howe "Communal Land Tenure and the Origin Descent Groups among the San BlasKuna", 1976, in: M. Helms e F. O. Loveland (eds.), Frontier Adaptions in Lower Central America. Philadelphia: ISHI. James Howe, 986. The Kuna Gathering. Austin: Texas University Pres. Las exogámicas que relatan los textos oficiales hacen referencia de relaciones entre mujeres cunas e ingleses de Jaimaica, tal vez el carácter estricto del que habla Howe en los cunas de hoy tenía excepciones en esta época. 


\section{Imagen 2}

Mapa particular del Golfo e Istmo del Darién ${ }^{42}$

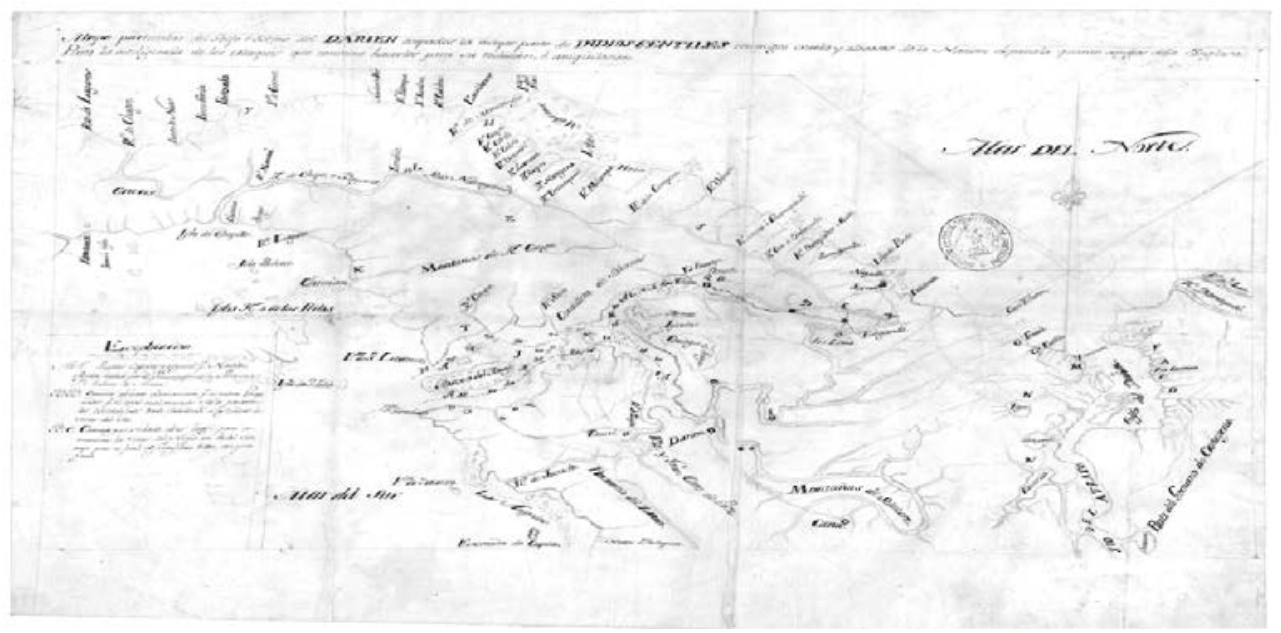

Fuente: Autor desconocido. Archivo General Militar de Madrid, Cartoteca ¿1778?

La labor de García y otros seis caciques de la zona fue resaltada por el gobernador Ariza ante el virrey. El control que ejercían en los poblados de indios reducidos y la importancia de su acompañamiento durante las expediciones a las zonas de frontera fue suficiente para que Ariza solicitara un aumento de sus salarios. Lo más relevante es que ellos estaban consiguiendo que los indígenas a su cargo cultivaran productos de la zona, enfatizaba el gobernador ${ }^{43}$. Sobre el valor de su trabajo en las expediciones, Ariza afirmaba:

“...porque siendo los nuestros tan astutos como aquellos, para conocer en la espesura y fragosidad del monte, no solo con la vista, sino con el olfato, propios de su desconfianza, los designamos de los rebeldes, desde esto que yo con el conocimiento, no emprendería sin el auxilio de dichos parciales acción alguna con

42 Ocupados la mayor parte por indios gentiles enemigos crueles y alevosos de la Corona española cuanto amigos de la inglesa. Para la inteligencia de los ataques que conviene hacernos para su rendición o aniquilación. Este mapa, a diferencia del elaborado por Ariza en 1774, tiene más información sobre la costa del Mar del Norte y posiblemente sea consecuencia de las expediciones de Bartolomé García.

43 AGN. Sección Colonia. Fondo Milicias y Marina. Legajo 116. "El gobernador del Darién repite a vuestra excelencia la solicitud de que se le de sueldo a los seis oficiales de indios, según vuestra excelencia y su antecesor lo tiene mandado. Capitán, teniente y alférez", 1779. Andrés Ariza, f. 836-847. 
seguridad; no para fiarme de su valor, pero sí de su conocimiento, lealtad y sutileza en el monte" ${ }^{44}$.

La iniciativa de conquistar a los indígenas integrándolos a la burocracia virreinal no era nueva. Fue impulsada con mayor rigor durante los años de la familia Carrisolio ${ }^{45}$. Esta política se aprobó a casusa de la disminución de indígenas reducidos en los poblados y, principalmente, por el impulso de las reformas promulgadas por José del Campillo ${ }^{46}$. Los beneficios de comerciar productos a cambio de la cristianización, desde la óptica de los funcionarios, podría conducir a la paz en esta zona, donde se habían levantado los pueblos de indios en contra de las autoridades. Como consecuencia a largo plazo, la persuasión fortaleció los vínculos entre líderes tribales y las autoridades españolas:

"Siempre que he necesitado alguno de dichos oficiales para mi dirección en estas compañías, habiendo acompañado de tres o cuatro indios de su confianza, que para costumbre del común del pueblo, para autoridad y custodia de sus personas la franquea dicho común armados y bastimentados, en cuya conformidad resulta que cuando se llama un oficial, concurren a lo menos al servicio cuatro hombres de satisfacción y conocimiento" ${ }^{47}$.

Pese a su importancia, Ariza conocía las tensiones entre los indios reducidos y los burócratas tribales, suscitadas por los constantes levantamientos al interior de los pueblos. En esa vía, el modelo de militarización de líderes tribales, necesitaba de otros dos frentes. Por una parte, era indispensable construir fuertes en la zona y por otra fomentar el poblamiento. Los fuertes eran lugares no solo de avanzada militar, también sirvieron para recibir a los pobladores de otras provincias del virreinato.

44 AGN. Sección Colonia. Fondo Milicias y Marina. Legajo 116. "Miguel Valcárcel, gobernador del Darién; su informe sobre hostilidades de los indios", 1775, f. 355.

45 Véase: Ignacio Gallup Diaz, The Door of the Seas and Key to Universe: Indian Politics and Imperial Rivalry in the Darien, 1640-1750 (Nueva York: Columbia University, 2004).

46 AGN. Sección Colonia. Fondo Milicias y Marina. Legajo 120. "Comercio de los indios del Darién: comunicaciones al respecto”, 1775. Andrés Ariza, f. 787-790.

47 AGN. Sección Colonia. Fondo Milicias y Marina. Legajo 116. "El gobernador del Darién repite a vuestra excelencia la solicitud de que se le de sueldo a los seis oficiales de indios, según vuestra excelencia y su antecesor lo tiene mandado", 1779. Andrés Ariza, f. 355. 


\section{Plan de construcción de fuertes: el otro eje de la reduc- CIÓN}

Los enfrentamientos de la Corona española contra los ingleses y franceses en el Caribe, durante la guerra de la oreja de Jenkins y los siete años, condujeron a la reorganización del sistema de fuertes militares de la zona. El Darién hacía parte de lo que algunos historiadores han llamado el "arco defensivo" del Caribe, que articulaba las plazas marítimas de tierra firme y las islas de Cuba, Puerto Rico y Santo Domingo. Este circuito conformaba las estaciones de los galeones provenientes del Perú y Nueva España ${ }^{48}$. El istmo del Darién era fundamental en este circuito Atlántico debido a su paso interoceánico, pero también por constituirse en un posible corredor de entrada para los enemigos al Virreinato del Perú.

Durante la década de los 70, se destinaron recursos desde España para fortalecer las guarniciones militares de esta zona. En las costas del Virreinato de la Nueva Granada, se pretendía reformar, principalmente, la plaza de Cartagena para que se convirtiera en el eje de articulación militar desde el Cabo de la Vela, en La Guajira, hasta la provincia de Veraguas ${ }^{49}$. Los recursos se dirigieron a mejorar las tropas y la construcción de fuertes militares. Estos cambios pasaban, inicialmente, por la profesionalización de las unidades de guarnición, impulsadas por militares enviados desde España ${ }^{50}$.

Antonio de Arévalo llegó al Virreinato de la Nueva Granada en 1741, un año después del ataque inglés a Cartagena y fue remitido con el propósito de arreglar los predios estropeados por los hostigamientos. Los planos de Arévalo permitieron el reconocimiento de la costa del Caribe, pero la información era escasa sobre el interior darienita. A finales de su primera estancia en el Darién, presionó al Concejo de Cartagena para que le autorizaran recursos tendientes a la construcción del primer fuerte militar

48 José Manuel Serrano Álvarez, "La gobernación de Cartagena de indias y el sistema defensivo indiano en el siglo XVIII”, Revista de Historia Militar Año XLIX No. 98 (2005): 37-75.

49 José Manuel Serrano Álvarez, "La gobernación de Cartagena de indias...", 40.

50 Para conocer la amplitud de la reforma véase: Juan Marchena Fernández, "La institución militar en Cartagena de Indias en el siglo XVIII” (Sevilla: Escuela de Estudios Hispano-Americanos, 1982). 
hecho con materiales y diseño moderno en la región. Los que existían eran estaciones para las guarniciones de la provincia, las cuales no contaban con seguridad que les permitiera salvaguardarse de los ataques. El fuerte de Yavisa, que se había erigido durante su estancia en el Darién, presentaba varios problemas que impedían la permanencia de tropas fijas. Los principales eran las inundaciones y la ausencia de ventilación ${ }^{51}$. Por esta razón, sugería a las autoridades que se erigiera uno nuevo que se utilizara como base para los acercamientos militares y persuasivos con los indios. Al respecto, lo justificaba de la siguiente manera:

"Servirá también de ir atrayendo poco a poco por medios suaves a los indios de aquella provincia, y atrayendo a los ingleses que hacen el comercio con ellos y les ayudan a la pesca de carey de que abundan sus costas, y a la que vienen todos los años por el mes de mayo: con estos objetos y otros de vitalidad muy grande al bien del Estado, y al que resultaría comercio, solicite de este un competente suplemento para dar principio a la expresada fortificación" 52 .

El tiempo pasó y los diputados del comercio no respondieron a la solicitud de Arévalo, quien además aconsejaba la edificación de caminos para contener a los indígenas que llegaban al Sinú a través del golfo. Caimán era el primero de un circuito de fuertes de la zona, donde también se pretendía construir en el río Bayano, en Urabá y en el río Turbo ${ }^{53}$. Este plan no solo necesitaba recursos para la construcción, sino también dependía de la llegada de unidades militares que acompañaran el desarrollo de las obras y sobre todo, de incentivos para poblar sus inmediaciones ${ }^{54}$. Arévalo perma-

51 AGMM. Fondo de Ultramar. Rollo (GD 57. 5-2-7-2). "Carta al virrey, obras en Caimán”, 1773. Antonio de Arévalo, f. 30.

52 AGN. Sección Colonia. Fondo Milicias y Marina. Legajo 135. “Agricultura del Darién: disposiciones para fomentarla”, 1774, f. 872.

53 AGMM. Fondo de Ultramar. Rollo (G.D.58.5-2-7-2). “Carta al virrey, obras en Caimán”, 1773. Antonio de Arévalo, f. 45.

54 La correspondencia entre Arévalo y el virrey nos hace pensar en los líos burocráticos para conseguir el presupuesto. También, el temor desde España y el virrey, de que no se utilizaran correctamente los fondos destinados. En efecto, las listas de materiales necesarios abundan de elementos que podían ser adquiridos sin el transporte desde Cartagena, como maderas, y algunos víveres. No obstante, Arévalo solicitó recursos para que los futuros vecinos pudieran ser autosuficientes. Para ese momento, ya existían algunos cultivos pertenecientes a los pobladores franceses. 
neció en la zona, a la espera de recibir el apoyo logístico de Cartagena, hasta que fue nombrado jefe de la expedición contra los indios de La Guajira.

Andrés Ariza retomó la preocupación de Arévalo y como muchos funcionarios de la época, le apostó al poblamiento de las zonas donde España no se había posicionado. Después de utilizar a los caciques-capitanes, se concentró en la construcción de fuertes militares y el traslado de familias europeas para avanzar por las fronteras autónomas. Las pocas familias que hubo en la zona provenían de las Islas Canarias, pero con los constantes ataques se replegaron a Cartagena, o en algunos casos fueron asesinadas ${ }^{55}$. Además de los fuertes, Ariza manifestó la necesidad de articular acciones conjuntas encaminadas a la reducción desde las gobernaciones circundantes a su provincia, lo que permitiría poblar de vecinos las costas del Caribe. El gobernador a diferencia de Arévalo recibió recursos y apoyo logístico que le permitieron construir algunas casas fuertes, cuya función principal era servir de anillo a las construcciones propuestas en la década pasada. Los ingresos dependieron durante estos años de los envíos presupuestales de Cartagena porque no existían cajas reales en la zona ni se desarrollaban labores productivas que permitieran al gobernador mayor autonomía; por esta razón la provincia fue favorecida por el aumento de recursos provenientes desde España para fortalecer las principales plazas marítimas del Caribe ${ }^{56}$.

De manera conjunta a las expediciones de balandras que se mencionaron, el gobernador ordenó la construcción de fuertes en las islas de Urabá, como la de Bocachica, donde las incursiones de indígenas autónomos lo impidieron. Los informes que van desde 1776 hasta 1782 mencionan la existencia efímera de guarniciones compuestas de cinco hombres en promedio, las cuales fueron arrasadas por los indios, como "Ipetiza", en las márgenes del Chucunaque. Las dificultades obligaron al gobernador a so-

55 AGN. Sección Colonia. Fondo Milicias y Marina. Legajo 120. "Comercio de los indios del Darién: comunicaciones al respecto", f. 791.

56 Es difícil cuantificar los recursos destinados para la política militar en el Darién, debido a la ausencia de recursos propios, pero durante la década del 70 se destinaron importantes cantidades que fueron registradas. Para conocer la distribución de los presupuestos desde Veraguas hasta La Guajira Véase: José Manuel Serrano Ávarez, "La gobernación de Cartagena de indias y el sistema defensivo indiano en el siglo XVIII", 37-75. 
licitar 2000 hombres de la guarnición fija de Cartagena, cuando el número de hombres en armas a su cargo no superaban las 80 unidades en total ${ }^{57}$. Para ese momento, quienes respondían a los ataques eran los indígenas reducidos, que tenían el interés de despojar a los rebeldes de las armas y herramientas que portaban ${ }^{58}$.

No solo los poblados nuevos fueron arrasados, Yavisa también fue destruida en $1780^{59}$. El proyecto principal, con el tiempo, dejó de ser la construcción de un fuerte militar en el río Caimán y pasó a la Loma de las Pulgas, cuyo valor estratégico radicaba en vigilar la entrada por el Atrato. Pero al igual que Yavisa, fue atacado por los indígenas que ocupaban el Chucunaque. El puesto de la Loma, destinado a la defensa del paso contra los ingleses, fue incendiado por los indios en $1780^{60}$.

\section{Imagen 3.}

Plano del río del Chocó que desagua en el golfo del Darién, en que se comprende la Loma de las Pulgas. $1781^{61}$

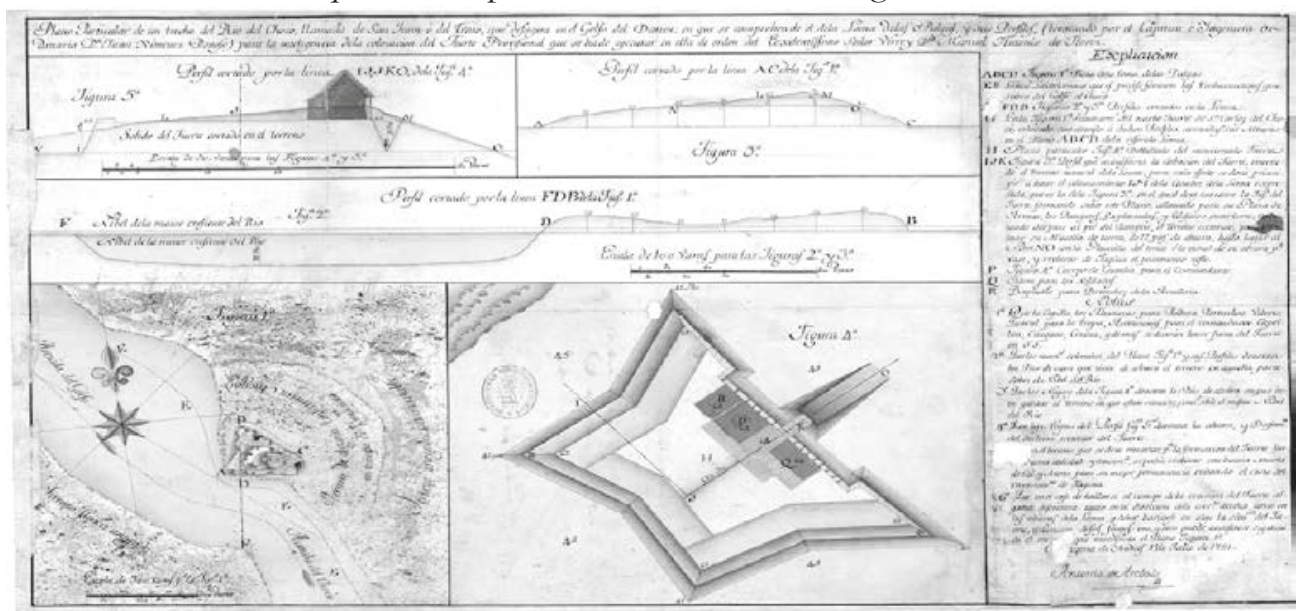

Fuente: Levantado por Juan Jiménez Donoso y realizado por Antonio de Arévalo. Archivo General Militar de Madrid, Cartoteca

57 AGMM. Fondo de Ultramar. Rollo (GD.5-2-7-2). "Descripción de la provincia del Darién, Gran Castilla de Oro", 1781, Andrés Ariza, f. 12.

58 AGMM. Fondo de Ultramar. Rollo (GD.5-2-7-2). "Descripción de la provincia del Darién...”, f. 15. 59 AGMM. Fondo de Ultramar. Rollo (GD.5-2-7-2). "Descripción de la provincia del Darién....”, f. 17. 60 AGMM. Fondo de Ultramar. Rollo (GD.5-2-7-2). "Descripción de la provincia del Darién....”, f. 20.

61 Este plano tenía otras dimensiones al erigido por Ariza. Los perfiles daban cuenta de la zona inundable y los cálculo para ello. El texto que lo acompaña son precisiones sobre el interior del fuerte. 
Todos los fuertes proyectados en la zona fueron saboteados por acciones militares de cunas autónomos. Ariza las relacionaba, al igual que otros funcionarios que transitaron la zona, con la capacidad de los cunas rebeldes de establecer intercambios comerciales con extranjeros, con quienes existían acuerdos para el saboteo. Ariza pensaba que el cierre de los pasos del comercio interétnico podría reducir a los indígenas a los pueblos españoles. Además de las evidencias halladas durante las incursiones, hubo una carta que el gobernador anterior encontró en Arquita, junto con vestimentas de guerra inglesas y un pasaporte de Jamaica. Esta decía lo siguiente:

"Whereas a firm pace, friendship and commerce is concluded between his britanick mayertys subjects and captain Tobi Fin who commands the river Kyman, this is therefore to require all his majestys subjects who shall go that way that they by no means* captain Tobi Fin, nor the Indies his jurisdiction but on the on all occasion assist them and treat them as friends" ${ }^{\prime \prime}$.

Este documento lo firmaba William Frelany Bart, capitán general, gobernador y comandante en jefe de Jamaica. La carta no solo demostraba las relaciones comerciales entre cunas e ingleses, también la formalización de la asistencia militar y logística contra los españoles. Los cunas habían establecido contactos con los europeos que transitaban las costas darienitas porque ellos tenían sistemas diplomáticos que les permitieron comercializar con foráneos sin ser subordinados ${ }^{63}$. Estas relaciones eran reforzadas por la adopción de los títulos jerárquicos ingleses, como el del capitán Tobi Fin. Según un informe posterior, los ingleses llegaron a la costa de Calidonia y nombraron capitanes que estuvieron al servicio de la Corona. La tendencia de preferir líderes tribales para negociar, de legitimidad efímera o ficticia, era compartida entre ingleses y españoles.

62 AGN. Sección Colonia, Fondo Milicias y Marina. Legajo 118. "Sierra Gregorio, gobernador de Cartagena; su comunicación sobre envío de armas al Darién e incidencias que hubo con los ingleses que explotaban cacao con los indios", f. 806. La carta fue traducida por orden del Gobernador de Panamá de la siguiente manera: "Habiéndose concluido una firma de paz, amistad y comercio entre los vasallos de su majestad británica y el capitán Tobías Fin que comanda el rio caimán, por tanto sirve esta de recurrir a todos los vasallos de su majestad que fuese a aquel pasaje que de ninguna manera molesten ni infieren al dicho capitán Tobías ni a los indios que están bajo su jurisdicción sino que el contrario en todas ocasiones les asistan y traten como amigos".

63 Carl Langebaek, “Cuna Long Distance Journeys. The Result of Colonial Interaction”, en: Ethnology Vol. 30 No. 4 (1991): 371-380. 
Si bien la diplomacia cuna con los imperios del Atlántico facilitó el acceso a armas de fuego, esta por sí sola no explica el alcance de los ataques contra los pueblos de indios reducidos y los poblados españoles. El manejo del lugar y principalmente la coordinación al momento de hostilizar fueron factores definitivos. No se trató de acciones espontáneas, guiadas por una actitud natural al salvajismo, como los funcionarios creían ${ }^{64}$. Los ataques consistían en emboscadas sorpresa durante la noche que aprovechaban la fragosidad de los bosques darienitas. Al respecto, Ariza comentaba:

"Para cometer los indios sus hostilidades, primero planean meses y acaso años enteros el número de hombres y modo que tiene el pueblo a que quieren acometer, las ventajas o defectos del terreno por donde se harían de retirar, las horas en que salen y vuelven, los vecinos de las labores, para dar golpe seguro, y así se vio en el pueblo del río Congo que el año de 68 entraron a sangre y fuego, estuvieron más de cinco años restándolo y tanteando" ${ }^{65}$.

Las hostilidades no eran únicamente a los poblados del virreinato. Los cunas también establecieron un circuito de vigilancia por los ríos más transitados, para así atacar las piraguas y balastaras de las expediciones virreinales. Los indígenas intervenían a los transeúntes en las orillas, donde podían refugiarse ante un posible desembarco. Ariza comentaba:

"Tomando puesto ventajoso en estos, de modo que los infelices incautos que se pasan para sus ejercicios, los sacrifican a su odio, echando inmediatamente a huir por la espesura, en donde por ningún caso los puedan castigar, y así está la constitución en que se hallan los miserables de esta provincia" ${ }^{\prime 66}$.

64 Aunque este grupo no era subalterno, vale la pena considerar las reflexiones que proponen los estudios subalternos, véase: Ranajit Guha, "La prosa de la contrainsurgencia", en: "Pasados poscoloniales. Comp: Saurabh Dube" (México: El Colegio de México, 1999). Y Ranajit Guha, "Elementary aspects of peasant insurgency in colonial india" (London: Duke, 1999). El clásico, a propósito de esta lectura de la agencialidad de grupos no hegemónicos, en: Antonio Gramsci, "Al margen de la historia. Historia de los grupos sociales subalternos”, Cuadernos de la cárcel. Cuaderno 25 (1934). Tomo VI (México: Universidad de Puebla. 1999).

65 AGN. Sección Colonia. Fondo Milicias y Marina. Legajo 122. "Andrés Ariza, gobernador del Darién, su informe sobre hostilidades de los indios", f. 389.

66 AGN. Sección Colonia. Fondo Milicias y Marina. Legajo 122. "Andrés Ariza, gobernador del Darién”, f. 392. 
Estas evidencias, que hacen parte de un gran compendio de informes de los ataques, cuestionan el argumento que sobrevalora las condiciones geográficas para explicar la escasa presencia española en la provincia darieni$\mathrm{ta}^{67}$.

\section{A MOdo DE CONCLUSIÓN}

Este artículo presentó las reformas militares en el Darién durante la primera década del gobierno de Ariza y sus consecuencias sociales. El estudio de las tensiones inter-étnicas en esta zona es de gran relevancia, ya que el Darién era una frontera que articulaba el Caribe y el Pacífico propicia para el encuentro de distintas fuerzas del Atlántico con los cunas. Las reformas fortalecieron la "burocracia indígena", principalmente la figura de los capitanes tribales, quienes se encargaron, sin mayor éxito, de contener los indígenas no conversos en los pocos poblados a cargo del gobernador Ariza. La apuesta por fortalecer los vínculos con los capitanes, por otro lado, permitió a los indígenas utilizar los presentes como estrategia para conseguir herramientas útiles que facilitaran la caza y la obtención de recursos para intercambiar con potencias enemigas de España. Como se presentó a lo largo de este artículo, existían otras figuras políticas al interior de los poblados cunas que fueron agentes de saboteo y que no fueron atraídos a la burocracia indígena. Por el contrario, la sobrevalorazión de los capitanes causó tensiones que provocaron levantamientos al interior de los pueblos.

La política de fuertes no prosperó en el Darién debido a los ataques permanentes de indígenas no reducidos, que organizaban sus pueblos en redes de parentesco y entablaron acciones conjuntas contra los españoles. Los fuertes fracasaron por la escasa presencia de efectivos militares enviados desde Cartagena y la dificultad de formar un ejército local entre los cunas. La diplomacia comercial con Inglaterra fue importante para la obtención de fusiles, así como el manejo del territorio y la organización confederativa de los grupos autónomos cunas. Esta situación sugiere que el marco de referencia metológica para atender a las confrontaciones hispano-indíge-

67 Esto contradice los postulados de Aline Helg, Liberty and Equality in Caribbean Colombia 17701835. (Chapel Hill: The University of North Carolina Press, 2004). Este argumento se sugirió en otro artículo, véase Nelson Eduardo Rodríguez, "El Imperio Contraataca: Las Expediciones Militares de Antonio Caballero y Góngora al Darién (1784-1790)”. Historia Crítica No. 4053 (August 1, 2014): 201-23. 
nas en el Caribe durante la segunda mitad del siglo XVIII debe considerar los aportes de la Historia Atlántica ${ }^{68}$. Los inconvenientes suscitados por la destreza cuna llevaron al virrey Antonio Caballero y Góngora a ordenar una expedición sin precedentes en la zona, donde convergieron funcionarios con experiencia en campañas de pacificación en otras provincias del Virreinato de la Nueva Granada.

\section{BiBLIOGRAFÍA}

\section{Archivos}

Archivo General de la Nación (AGN), Bogotá-Colombia. Sección Colonia, Fondos: Milicias y Marina, Virreyes, Quinas y Miscelánea.

Archivo Histórico Militar de Madrid (AGMM). Madrid-España. Fondos: Cartoteca y Fondo de Ultramar.

\section{Documentación primaria impresa}

Ariza, Andrés. "Comentarios de la rica y fertilísima provincia del Darién 1774". En La gobernación del Darién a finales del siglo XVIII. editado por Baquero, Álvaro y Antonio Vidal. Uninorte, 2004.

Guiror, Manuel. "Instrucción que deja a su sucesor en el mando". En Relaciones e informes de los gobernantes de la Nueva Granada, editado por Germán Colmenares. Bogotá: Banco Popular, 1989, Vol. 1. Messia De la Zerda, Pedro. "Relación del estado del virreinato de Santa Fe", (1772). En Relaciones e informes de los gobernantes de la Nueva Granada, editado por Germán Colmenares. Bogotá: Banco Popular, 1989, Vol. 1.

Walburguer, Jacobo. "Relación de la provincia del Darién" (1748). En El diablo vestido de Negro y los cunas del Darién en el siglo XVIII. editado por Carl Langebaek. Bogotá: Uniandes, 2006.

\section{Fuentes secundarias}

Baquero, Álvaro y Antonio Vidal. La gobernación del Darién a finales del siglo XVIII. El informe de un funcionario ilustrado. Barranquilla: Uninorte, 2004.

68 Turner Amy, "Indigenous America and the Limits of the Atlantic world, 1493-1825", en: Greeme Jack y Morgan Phill (Ed), Alantic History: A critical appraisal. New York: Oxford University. 2009. 
Gallup Diaz, Ignacio. “The Spanish Attempt to Tribalize the Darién, 173550”. Ethnohistory, 49, 2 (2002): 281-317.

Gallup Diaz, Ignacio. "The Door of the Seas and Key to Universe: Indian Politics and Imperial Rivalry in the Darien, 1640-1750". Nueva York: Columbia University, 2004.

García, Claudia. Etnogénesis, hibridación y consolidación de la identidad del pueblo Miskitu. Madrid: Consejo Superior de Investigaciones Científicas, 2007.

Gramsci, Antonio. "Al margen de la historia. Historia de los grupos sociales subalternos". En Cuadernos de la cárcel, Cuaderno, 25 (1934), Tomo VI. México: Universidad de Puebla, 1999.

Guha, Ranajit. "La prosa de la contrainsurgencia". En Pasados poscoloniales. Comp. Saurabh Dube. México: El Colegio de México, 1999.

Guha, Ranajit. Elementary aspects of peasant insurgency in colonial india. London: Duke, 1999.

Gómez Gonzales, Juan Sebastián. "Las tensiones de una frontera ístmica: alianzas, rebeliones y comercio ilícito en el Darién, siglo XVIII". En Historia y Sociedad, No. 15 (2008): 143-163.

Howe, James. "Communal Land Tenure and the Origin Descent Groups among the San BlasKuna". In Frontier Adaptions in Lower Central America, editado por M. Helms e F. O. Loveland. Philadelphia: ISHI, 1976.

Howe, James. The Kuna Gathering. Austin: Texas University Press, 1986. Kuethe, Allan. "Carlos III: absolutismo ilustrado e imperio americano". En Soldados del Rey: El ejército borbónico en América colonial en vísperas de la independencia, editado por Allam Kuethe y Juan Marchena. Barcelona: Universidad Jaume I, 2005, 17-30.

Kuethe, Allan. "The Pacification Campaign on the Riohacha Frontier, 1772-1779". The Hispanic American Historical Review, Vol. 50 No. 3 (1970): 467-481.

Fisher, John. "Imperial reforms and rivalries". En A companion to Latin American history, editado por Thomas Holloway. John Wiley \& Sons, 2011.

Polo Acuña, José. Indígenas, poderes y mediaciones en La Guajira en la transición de la Colonia a la República (1750-1850). Bogotá: Uniandes, 2012. 
Langebaek, Carl. "Cuna Long Distance Journeys. The Result of Colonial Interaction”, Ethnology, Vol. 30 No. 4 (1991): 371-380.

Langebaek, Carl. El diablo vestido de negro y los cunas del Darién en el siglo XVIII. Bogotá: Uniandes, 2006.

Lucena Giraldo, Manuel. "Las nuevas poblaciones de Cartagena de Indias. 1774-1794”. Revista de Indias, Vol. LIII No. 199 (1999): 762-781.

Marchena Fernández, Juan. La institución militar en Cartagena de Indias en el siglo XVIII. Sevilla: Escuela de Estudios Hispano-Americanos, 1982.

Peralta, Jaime. "Los cuna y sus saberes médicos. La "ciencia” de los "bárbaros" bajo la mirada del mundo ilustrado", Historia Crítica, No. 46 (2012): 44-65.

Rodríguez, Nelson Eduardo. "El Imperio Contraataca: Las Expediciones Militares de Antonio Caballero y Góngora al Darién (1784-1790)”. Historia Crítica, No. 40 Vol. 53 (2014): 201-23.

Rogers, Nicholas. "Caribbean Borderland. Empire, Ethnicity, and the Exotic on the Mosquito Coast", Eighteenth-Century Life, Vol. 26, No. 3. Serrano Álvarez, José Manuel. "La gobernación de Cartagena de indias y el sistema defensivo indiano en el siglo XVIII", Revista de Historia Militar, Vol. XLIX No. 98 (2005): 37-75.

Turner, Amy. "Indigenous America and the Limits of the Atlantic world, 1493-1825”. En Alantic History: A critical appraisal, Jack Greeme y Phill Morgan. New York: Oxford University, 2009.

Weber, David. Spanish Bourbons and Wild Indians (Charles Edmondson Historical Lectures). Waco, TX: Baylor University Press, 2004.

Weber, David. Bárbaros: los españoles y sus salvajes en la era de la Ilustración. Madrid: Crítica, 2005.

Para citar este artículo: Rodríguez Hernández, Nelson Eduardo. "La amenaza cuna: política de indios del gobernador Andrés Ariza en el Darien durante su primera década de gobierno en el siglo XVIII", Historia Caribe Vol. XI No. 28 (Enero-Junio 2016): 211-239. DOI: http://dx.doi. org/10.15648/hc.28.2016.9 